TITLE:

\title{
Cooperative web sharing against predators promotes group living in spider mites
}

AUTHOR(S):

Yano, Shuichi

CITATION:

Yano, Shuichi. Cooperative web sharing against predators promotes group living in spider mites. Behavioral Ecology and Sociobiology 2012, 66(6): 845-853

ISSUE DATE:

2012

URL:

http://hdl.handle.net/2433/153051

\section{RIGHT:}

The final publication is available at www.springerlink.com; This is not the published version. Please cite only the published version.; この論文 は出版社版でありません。引用の際には出版社版をご確認ご利用くだ さい。 
1 Cooperative web sharing against predators promotes group living in spider

2 mites

3

4 Shuichi Yano

5 Affiliation: Laboratory of Ecological Information, Graduate School of Agriculture,

6 Kyoto University,

7 Address: Sakyo-ku, Kyoto 606-8502, Japan

8 e-mail: yano@kais.kyoto-u.ac.jp

$9 \quad$ Tel.: 81-75-753-6144

$10 \quad$ Fax: 81-75-753-6144 
11 Abstract I examined spider mite cooperative web sharing against predation as a

12 factor promoting group living. Tetranychus urticae and Tetranychus kanzawai infest

13 leaf surfaces under webs made of silk threads. Experimental observation of predation

14 by the predatory mite Euseius sojaensis on spider mites of different group sizes

15 revealed that fewer spider mites were preyed upon when the web-building period

16 before the attack was prolonged, suggesting that established webs help protect spider

17 mites. Moreover, per capita predation on spider mites was diluted in larger groups.

18 This was not due to predator satiation but seemingly because webs had been

19 completed while the initial prey was consumed. Spider mites lived more closely

20 together in the presence of a predator, showing that the degree of group living is

21 facultative. In the presence of a preceding spider mite with an established web, a

22 newcomer spider mite gain protection by taking residence in the established webs;

23 sharing the web was not disadvantageous for the preceding mite. The proportion of

24 individuals preyed upon did not differ between preceding and newcomer mites, suggesting that there was no interference against the latter. These interactions were 
27 indirect interaction between mites sharing fresh webs, cooperative web sharing

28 seemed to be a major force promoting group living in the spider mites. Moreover, the

29 distances between spider mites did not differ between heterospecific and conspecific

30 groups, demonstrating that mites living together do not distinguish between species;

31 hence, heterospecific mites may cooperate and live together in the same manner as

32 conspecifics.

33

34 Key words Apparent interspecific cooperation • dilution effect • group size - indirect

35 interaction - cooperative web sharing 
Introduction

37 Individuals living in a group can reduce their risk of predation by means of cooperative defense, the dilution effect, and by early warning (Krause and Ruxton 2002 and references therein). On the other hand, group members incur costs in terms of increased exposure to natural enemies and increased intraspecific competition

41 (Fitzgerald 1993; Rasa 1997; Prokopy and Roitberg 2001). Therefore, the degree of conspecific aggregation should reflect the costs and benefits of group living (Rasa 1997; Spieler 2003; Semeniuk and Dill 2004; Despland and Huu 2007). From this viewpoint, heterospecific individuals may also live together in a group when the benefit of interspecific grouping to individuals overwhelms the cost of interspecific competition between them. These interspecific interactions have been reported among conspecific organisms such as birds (Krams and Krama 2002), spiders

48 (Hodge and Storfer-Issera 1997), shellfishes (Briones-Fourzan et al. 2008), and mammals (Barry and Mundy 2002). This study reports that related spider mite species with common potential predators live together and cooperate in the same manner as conspecifics; this co-habitation is probably a byproduct of intraspecific 
cooperation.

$$
\text { Tetranychus urticae and Tetranychus kanzawai are polyphagous spider mites }
$$

(e.g., Jeppson et al. 1975; Gotoh et al. 1999). They live together on dozens of wild and cultivated host plant species and often co-occur on the same plant specimen (Kondo and Takafuji 1985; Morishita 1992; 1997; Takafuji and Morishita 2001;

Osakabe et al. 2002; Ohno et al. 2010). Mated mite adult females (founder individuals) construct complicated, irregular webs on leaf surfaces (Saito 1983), feeding and reproducing inside the webs, and ultimately forming aggregations that include juveniles that also contribute to the web building (Hazan, 1974; Clotuche et al., 2009). Mated adult females of these mites disperse to new hosts, primarily by walking (Kondo and Takafuji 1985; Margolies and Kennedy 1985; Morishita 1992; 1997). Ambulatory dispersing adult females of T. urticae often follow trails left by preceding females and join webs built by conspecifics, which results in group living at a new colony site (Yano 2008). Although mites normally aggregate on their host plants (Strong et al. 1997; Oku et al. 2005; Yano 2008), a typical tetranychid colony in the wild contains less than five adult females (Yano, unpublished data). 
As an ultimate factor promoting conspecific group living of spider mites,

cooperative defense against predators using webs has been reported in the bamboo

spider mite Stigmaeopsis longus (Saito 1986a; 1986b; Mori et al. 1999). In contrast,

71 virtually no attention has been paid to the benefit of group living as cooperative

defense in either T. urticae and T. kanzawai. This may be because spider mites of this

genus never exhibit aggressive defensive behaviors, though aggressive defense

against predators does occur in mites belonging to the genus Stigmaeopsis and in

social caterpillars (McClure and Despland 2011). Another reason for the lack of

attention to the benefit of cooperative defense in Tetranychus may be that specialist

predatory mites such as Phytoseiulus persimilis and Neoseiulus womersleyi can

easily suppress spider mite populations at high densities (e.g., Chant 1961;

79 Hamamura 1986), which implies that collective webs are ineffective as a defense.

80 However, the apparently antagonistic interactions between spider mites and

81 specialist predatory mites may only be one potential outcome because spider mite

82 webs should exclude remaining potential predators. Indeed, some studies have 
et al. 1970; Sabelis and Bakker 1992). Therefore, interactions between spider mites and generalist predatory mites should be examined as a factor promoting spider mite group living. In general, the effectiveness of a defensive trait against potential enemies becomes apparent only when the trait is absent. For example, some myrmecophytes are only heavily attacked by herbivorous insects when symbiont ants, i.e., the defensive trait of the plant, are artificially excluded from the plants (Vasconcelos

91 1991; Gaume et al. 1997). From this viewpoint, antagonistic interactions between spider mites and potential predators will be detectable only before founder spider

93 mite females (that had dispersed from previous host plants) complete webs on new

94 host plants. Euseius sojaensis is a generalist predatory mite that feeds on plant 95 products and many spider mite species (Osakabe et al. 1986; Amano 1996).

96 Although E. sojaensis cannot penetrate completed spider mite webs (Osakabe 1988;

97 Ozawa and Yano 2009), the predatory mite readily preys on spider mites outside the webs (Ozawa and Yano 2009). Therefore, the predator is considered to be a typical potential predator of T. urticae and T. kanzawai. 
100 In this study, I examine why the spider mite species T. urticae and T. kanzawai

101 live in groups, and why different spider mite species may live close together, by

102 investigating cooperative web sharing against the potential predator E. sojaensis.

\section{Materials and methods}

108 Single populations of the two spider mite species were collected in Kyoto, Japan;

109 that of T. urticae (green form) was collected from a rose garden, and the T. kanzawai

110 population was collected from a strawberry garden. Both populations were

111 maintained on expanded primary leaves of the kidney bean Phaseolus vulgaris

112 (Leguminosae), pressed onto water-saturated cotton in Petri dishes (90-mm diameter,

113 14-mm depth). The E. sojaensis study population was collected from kudzu vines

114 Pueraria lobata (Willd) Ohwi (Leguminosae) in Kyoto and was reared on tea pollen

115 on $50 \times 50-\mathrm{mm}$ squares of Parafilm (Parafilm M; American National Can Co., 
116 Chicago, IL, USA) placed on water-saturated cotton in Petri dishes (for details, see

117 Shirotsuka and Yano 2011). The dishes were placed in transparent plastic containers

118 and kept at $25 \pm 2^{\circ} \mathrm{C}$ and $50 \pm 5 \%$ relative humidity, with a photoperiod of 16L8D

119 (hereafter described as "laboratory conditions”).

120 Adult females of the spider and predatory mites used in the following

121 experiments were similar in size $(\leq 0.5 \mathrm{~mm})$. Detailed observations and transfer using

122 a fine brush were possible only under a stereomicroscope. Webs are usually invisible

123 even under a microscope (e.g., Clotuche et al. 2009). Because mated adult females

124 represent the dispersing stage of spider mites, I used 2- to 4-day-old mated females

125 (hereafter "females”) of T. urticae and T. kanzawai in the following experiments. By

126 using these females as prey, I simulated an early stage of web building in the

127 presence or absence of predators.

129 Effects of group size and webs on predation rates on spider mites

131 To examine effects of spider mite group size and the degree of web building on 
predation by E. sojaensis, I confined different numbers (1, 2, and 4) of each spider used bean leaf squares of the same size. One to four adult females correspond to a

135 typical colony size of tetranychid mites in the wild (Yano, unpublished data). I then introduced an E. sojaensis female onto each leaf square after different time lags (0, 1, 4, and $24 \mathrm{~h}$ ), which allowed spider mites to build different degrees of webs before predator attack. I did not monitor at more frequent intervals because spider mites

139 seem to have diurnal rhythms (e.g., Clotuche et al. 2011). I used 3- to 5-day-old starved E. sojaensis females that had previously been isolated for $48 \mathrm{~h}$ in $1.5-\mathrm{ml}$

141 microtubes (Treff AG, Degersheim, Switzerland) with a water droplet. This was to

142 promote immediate predation and to easily judge predation, because the transparent

143 body of a starved predator turns a vivid vermillion after consuming prey. Thereafter,

144 all starved E. sojaensis were prepared in the same manner. No E. sojaensis females

145 died during the starvation treatment. The number of replicates for each combination

146 of group sizes and time lags was $>20$. Preliminary experiments showed that

147 predation by a starved E. sojaensis female on a T. urticae or a T. kanzawai female on 
148 a leaf square reached a plateau $12 \mathrm{~h}$ after introduction (Fig. 1). Therefore, the

149 proportion of consumed prey (predation rates) in all experiments was measured $24 \mathrm{~h}$

150 after predator introduction. The data were analyzed with a Wald test (SAS Institute

151 Inc. 1998).

152 To examine whether satiation of the predators may have limited predation rates

153 of the above experiment, potential consumption by E. sojaensis was measured. To

154 prepare living prey females that do not walk or produce webs, I used adult females

155 of T. urticae and T. kanzawai that had been subjected to a sub-lethal intensity of

156 ultraviolet irradiation (253.7-nm wavelength, $0.45 \mathrm{~W} \mathrm{~m}^{-2}$ for $1 \mathrm{~h}$ ) using a GL-6

157 sterilization lamp (6 W; Ultra-Violet Box, Sogorikagaku Glass Works Co., Kyoto,

158 Japan). I supplied four prey females to each starved predatory mite on a leaf square.

159 After $24 \mathrm{~h}$, the number of consumed prey was recorded.

To examine whether spider mite eggs deposited during the experimental period

may have affected predation rates in the experiment, egg consumption by $E$. sojaensis in the same period was examined. I confined a female of each spider mite 
164 minimal damage to the webs, and counted the number of eggs laid. All spider mite

165 eggs were deposited within webs. I then introduced a starved E. sojaensis onto each

166 leaf square. After another $24 \mathrm{~h}$, I counted the number of consumed eggs.

Degree of spider mite group living in response to a predator

170 To examine whether spider mites lived together in response to predators, I measured

171 the distance between pairs of spider mite females in relation to predator presence. I

172 introduced two females onto each of 24 leaf squares for each spider mite species. To

173 avoid predation during observation, I allowed the females to build webs for $24 \mathrm{~h}$

174 under laboratory conditions, after which the females were sufficiently protected by

175 webs (see "Results”). I then introduced one starved E. sojaensis female each onto

176 half of the leaf squares ( $\mathrm{n}=12$, predator presence) for each spider mite species while

177 the rest of the squares served as controls ( $n=12$, predator absence for each species).

178 Because the body length of $E$. sojaensis was $<0.5 \mathrm{~mm}$, leaf area occupied by the

179 predator was $<1 / 1,000$ of the leaf square, which may be considered negligible. After 
1801 1, 4, and $24 \mathrm{~h}$, I measured the distances between the centers of the idiosomas of the

181 female spider mites to the nearest $1 \mathrm{~mm}$ as a degree of group living. As decimal

182 fractions were rounded off, the minimum distance was $1 \mathrm{~mm}$. A replicate (T. urticae,

183 predator absence) in which a spider mite female escaped from the leaf square was

184 excluded from the data. A three-way ANOVA (SAS Institute Inc. 1998) was then

185 performed on square root-transformed data.

186

187 Pros and cons of lodging and hosting spider mites in the presence of a predator

189 To simulate the conditions in which a preceding spider mite female has already

190 established a web, an initial female (hosting female) was introduced to a leaf square.

191 After $24 \mathrm{~h}$, when the whole surface of the leaf square was more or less covered by

192 web, a second lodging female and a starved E. sojaensis female were introduced to

193 the square. To discriminate between conspecific spider mites, I randomly selected

194 one and marked it with a dab of blue pigment ink on the dorsal setae. I examined

195 four combinations (i.e., TuTu, $T k T k$, $T u T k$ and $T k T u$ ) of the two spider mite species. 
196 The number of replicates for each combination was $>20$. Predation rates were

197 measured $24 \mathrm{~h}$ after predator introduction.

To examine costs and benefits of hosting and lodging, predation rates on

199 hosting and lodging females were compared with those in the absence of respective

200 partners. Thus, the predation rate on lodging females was compared with that of

201 solitary females without webs (group size $=1$, time lag $=0 \mathrm{~h}$ in the above

202 experiment) while that on hosting females was compared with that on solitary

203 females with webs (group size $=1$, time lag $=24 \mathrm{~h}$ ). The rates were compared using

204 Fisher's exact probability test.

206 Indirect interaction between spider mites sharing webs in the absence of a predator

208 Indirect interactions among herbivores include both exploitative competition and

209 plant-mediated interactions (e.g., Kaplan and Denno 2007). To examine whether

210 there were either competitive or facilitative indirect interactions between spider mite

211 females sharing webs, I introduced one female (initial female) onto each of forty 10 
$212 \times 10-\mathrm{mm}$ leaf squares per species (T. urticae and T. kanzawai); 40 squares served as

213 controls without initial females. These leaf squares were maintained under

214 laboratory conditions. After $24 \mathrm{~h}$, I carefully removed the initial females with

215 minimal damage to the webs, and counted the number of eggs laid. I then introduced

216 one T. urticae female (test female) each onto half of the leaf squares in each

217 treatment and one T. kanzawai female (test female) onto each of the remaining

218 squares. After another $24 \mathrm{~h}$, I counted the cumulative egg numbers laid and

219 calculated egg numbers laid by each test female by subtracting the egg number of the

220 initial female from the cumulative number. Because the number of eggs laid within a

221 certain period is considered the most sensitive performance index of spider mite

222 females (Yano et al. 1998; Gotoh et al. 1999; Agrawal 2000; Yano et al. 2003), any

223 indirect interaction, either exploitative competition or plant mediated interaction,

224 between females sharing webs should result in lower (or higher) egg numbers laid by

225 the test female. A one-way ANOVA (SAS Institute Inc. 1998) was performed on the

226 data for each test female species. 
Do spider mites living together distinguish between species?

229

230 To examine whether females living together distinguish between species, I

231 introduced two females onto a $15 \times 15-\mathrm{mm}$ leaf square in the following

232 combinations: two T. urticae $(\mathrm{n}=32)$, two T. kanzawai $(\mathrm{n}=31)$, or one female of

233 each species $(n=33)$. I then measured the distances between females to the nearest 1

$234 \mathrm{~mm}$ at $3,6,12,24$, and $48 \mathrm{~h}$ after the introduction. A one-way ANOVA (SAS

235 Institute Inc. 1998) was performed on square root-transformed data for each time 236 point.

237

$238 \quad$ Results

239

240 Effects of group size and webs on predation rates on spider mites Both group size and time lag for web building had significant effects on per 
244 with increased time lag indicates that completed webs may effectively defend spider

245 mites from predation while decreased (per capita) predation with increasing group

246 size indicates a dilution effect (Fig. 2). Each E. sojaensis individual consumed less

247 than one spider mite in average.

248 The number ( \pm SE) of immobilized spider mites consumed by E. sojaensis

249 individuals in $24 \mathrm{~h}$ was $2.24 \pm 0.17(\mathrm{n}=21)$ for $T$. urticae and $3.30 \pm 0.16(\mathrm{n}=20)$

250 for T. kanzawai. These results demonstrate that predators consuming at most one

251 living spider mite in a 24-h period in this experiment were not satiated. Predators

may have consumed less active spider mites rather than those that were immobilized

253 because of the protection provided by webs and the mobility of prey mites (possible

254 avoidance behavior).

In addition, the number ( $\pm \mathrm{SE}$ ) of spider mite eggs consumed by $E$. sojaensis

$(n=13)$, respectively. 
Degree of spider mite group living in response to a predator

262 The distances between females differed significantly with respect to the presence of

263 a predator (Table 2), although the differences became less obvious over time after

264 predator introduction (Fig. 3). Thus, spider mite females lived more closely together

265 in response to predator presence. In addition, no spider mites were preyed upon

266 during this experiment.

268 Pros and cons of lodging and hosting spider mites in the presence of a predator

270 The predation rates on lodging and hosting females did not differ significantly (Table

2713 , comparison A), suggesting that there was no interference against lodging females.

272 Indeed, interference behaviors among females were never observed. Moreover, the

273 predation rate on lodging females was lower than that on solitary mites without webs

274 (Table 3, comparison B); the predation rate on hosting females did not differ from

275 that on solitary females with webs (Table 3, comparison C). These patterns were 
consistent across all combinations of spider mite species.

277

278 Indirect interaction between spider mites sharing webs in the absence of a predator

The number of eggs laid by a test female within $24 \mathrm{~h}$ did not differ among treatments

281 for either T. urticae (Fig. 4a), T. kanzawai (Fig. 4b), indicating that there was

282 virtually no indirect interaction between heterospecific and conspecific mites sharing

283 fresh webs.

Do spider mites living together distinguish between species?

287 Up to $24 \mathrm{~h}$ after introduction, the average distance between spider mite females was

approximately $3 \mathrm{~mm}$ (on a $15 \times 15-\mathrm{mm}$ square) for all combinations. That is, the 
h) (Fig. 5). These data show that spider mite females living together do not

distinguish between species.

\section{Discussion}

297 The decrease in predation on spider mites with increased time lag for web building

298 indicates that established webs protected spider mites from predation. Previous

299 studies (McMurtry et al. 1970; Osakabe 1988; Sabelis and Bakker 1992; Ozawa and

300 Yano 2009) also report that established spider mite webs are effective against

301 generalist predators. Although spider mite webs contain many eggs, all eggs are

302 deposited within webs where E. sojaensis cannot easily access. Therefore, E.

303 sojaensis consumed only a small fraction of the eggs. Moreover, considering the

304 relative size of a spider mite $(0.5 \mathrm{~mm})$ and an egg $(<0.15 \mathrm{~mm}$; Crooker 1985$)$, effects

305 of egg consumption on predation rates seemed negligible, if any. Compared with the

306 spider mite short generation time of about 10 days at $25^{\circ} \mathrm{C}$, a web establishment

307 period as long as $24 \mathrm{~h}$ may be considerable. Therefore, any trait that reduces 
predation risk during this 24-h period should confer selective advantage to the spider

mites. From this viewpoint, group living during web production seems to reduce the predation rate on spider mites. This dilution effect was not due to the satiation of

311 predatory mites because they had the potential to consume more than twice the number of immobilized prey in the same period. Therefore, it is likely that the tested predatory mites were unable to consume more living prey because webs had been

314 completed beforehand. that the degrees of group living in the two spider mite species are facultative; i.e., the

317 benefit of closer group living in the presence of a predator may outweigh its possible cost. Because no spider mite was preyed upon in the presence of previously

319 established webs, indirect cues for predator presence, e.g., odors from injured conspecifics (Grostal and Dicke 1999; Oku et al. 2003), may be ruled out; the spider mites living closely together may have instead detected direct cues for predator presence, e.g., odors and wastes (Grostal and Dicke 1999, 2000; Pallini et al. 1999). 
over time probably because amount of established webs may have affected spider

mites' behaviors and/or because they became increasingly aware that predators were

unable to access them.

conspecific webs (Yano 2008). The benefit of these behaviors was explicitly presence of a predator and a preceding spider mite with an established web, a secondarily introduced (lodging) female gained protection from predation by lodging in the web: sharing the web was not a disadvantage for the hosting female. This asymmetric cost-benefit of lodging and hosting females seems to explain why they

334 shared webs. Otherwise, if the benefit of a lodging individual were achieved at a cost

335 for the hosting individual, such altruistic behavior should have evolved only between conspecific relatives. Moreover, the proportion of predated individuals did not differ

337 between hosting and lodging mites, suggesting that there was no interference against

338 the latter. The above interactions were consistent in pairs of heterospecifics, 339 indicating that spider mites sharing webs do not distinguish between species. 
Although there was no direct interference between spider mites sharing webs,

341 living in proximity to others may have fitness costs associated with indirect

342 competition, i.e., exploitive and/or plant-mediated competition (Tilman 1982;

343 Kaplan and Denno 2007). However, such indirect competition seemed negligible

344 both within and between spider mite species sharing webs. Because the feeding

345 modes of the two related spider mite species were identical, fine-scale resource

346 partitioning between individuals living in close proximity (e.g., Daugherty 2009)

347 seems unlikely. Oku et al. (2009) demonstrated a web-building cost for T. urticae

348 adult females in terms of reduced egg production during the initial $24 \mathrm{~h}$ of web

349 building. Therefore, females introduced secondarily may have offset the costs of

350 possible indirect competition with initial females by reducing web-building costs,

351 that is, by sharing established webs. There may be some competition after web

establishment, i.e., following the initial $24 \mathrm{~h}$ of web building; however, living in 
feeding within webs that are extended over leaf surfaces, leading to heavy infestation

357 (Yano, unpublished data). Web extension in this manner is reflected in Figure 5,

358 which shows that between-female distances increased slightly after $24 \mathrm{~h}$ of web

359 building. Therefore, living in proximity to others during web establishment should

360 always be advantageous in the end, perhaps explaining why the spider mites always

361 live in groups. Le Goff et al. (2010) reported significant positive group effects on

362 egg production in T. urticae virgin females. However, such a positive group effect on

363 egg production was not detected in the present experiment using mated females (i.e.,

364 dispersing stage) of the two spider mite species. al. 2002; Ohno et al. 2010) and have the potential to live closely together on a single leaf, as demonstrated here, strong natural selection for heterospecific cooperation (in comparison to conspecific cooperation) remains questionable. The apparent cooperation between heterospecifics may rather be a byproduct of cooperation 
some extent between heterospecific and conspecific mates before copulation (Ozawa distinguish between species when living together on a leaf likely indicates that some advantage is gained by sharing webs with heterospecifics.

kanzawai (Ozawa and Takafuji 1987), indicating that they are distinct biological raises the question of how the two distinct species evolved. The most plausible explanation may be allopatric speciation; T. urticae expanded its distribution to southwestern areas of Japan (Kyoto) as recently as the late 1970s (Gotoh and Shinkaji 1981).

Although spider mite webs afford effective protection against generalist predatory mites, the webs are ineffective against mites that specialize in preying on web-spinning spider mites (McMurtry et al. 1970; Sabelis and Bakker 1992). This is an example of apparent trade-offs in adaptation to different prey (Levins and 
MacArthur 1969). Moreover, some specialist predatory mites use spider mite webs

389

as prey-searching cues (Pratt and Croft 1999; Roda et al. 2001; Furuichi et al. 2005).

Therefore, group living of spider mites may be costly against such specialist

predatory mites. This possible trade-off in cooperative web sharing against specialist

and generalist predatory mites may in turn determine spider mite optimal group sizes

in the wild; this is a topic that remains to be addressed in future investigations.

Acknowledgments I thank Dr. T. Czeschlik, Dr. J. C. Choe, and anonymous

he has no conflict of interest.

\section{References}

Agrawal AA (2000) Host range evolution: adaptation and trade-offs in fitness of 
404 Amano H (1996) Natural enemies. In: Ehara S, Shinkaji N (eds) Principles of Plant

Barry RE, Mundy PJ (2002) Seasonal variation in the degree of heterospecific association of two syntopic hyraxes (Heterohyrax brucei and Procavia capensis) exhibiting synchronous parturition. Behav Ecol Sociobiol 52:177-181

Briones-Fourzán P, Ramírez-Zaldívar E, Lozano-Álvarez E (2008) Influence of conspecific and heterospecific aggregation cues and alarm odors on shelter choice by syntopic spiny lobsters Biol Bull 215:182-190

Chant DA (1961) An experiment in biological control of Tetranychus telarius (L.) (Acarina: Tetranychidae) in a greenhouse, using Phytoseiulus persimilis Athias-Henriot (Phytoseiidae). Can Entomol 93:437-443

417 Clotuche G, Mailleux AC, Astudillo FA, Deneubourg JL, Detrain C (2011) The 
420

Crooker A (1985) Embryonic and juvenile development In: Helle W, Sabelis MW (eds) Spider Mites: their Bilology, Natural Enemies and Control. Vol. 1A Elsevier, Amsterdam, pp 149-163

Daugherty MP (2009) Specialized feeding modes promote coexistence of competing herbivores: insights from a metabolic pool model. Environ Entomol 38:667-676

Despland E, Huu AL (2007) Pros and cons of group living in the forest tent caterpillar: separating the roles of silk and of grouping. Entomol Exp Appl 122:181-189

Fitzgerald TD (1993) Sociality in caterpillars. In: Stamp NE, Casey TM (eds) Caterpillars: ecological and evolutionary constraints on foraging. Chapman \& Hall, New York, pp 372-403

Furuichi H, Yano S, Takafuji A, Osakabe Mh (2005) Prey preference of the predatory mite Neoseiulus womersleyi Schicha is determined by spider mite webs. J Appl Entomol 129:336-339

Gaume L, Mckey D, Anstett MC (1997) Benefits conferred by “timid” ants: active anti-herbivore protection of the rainforest tree Leonardoxa africana by the 
Gotoh T, Shinkaji N (1981) Critical photoperiod and geographical variation of diapause induction in the two-spotted spider mite, Tetranychus urticae Koch (Acarina: Tetranychidae). Jap J Appl Entomol Zool 25:113-118 (in Japanese, with English summary)

441 Gotoh T, Gomi K, Nagata T (1999) Incompatibility and host plant differences among populations of Tetranychus kanzawai Kishida (Acari: Tetranychidae). Appl Entomol Zool 34:551-561

444 Grostal P, Dicke M (1999) Direct and indirect cues of predation risk influence behavior and reproduction of prey: a case for acarine interactions. Behav Ecol $10: 422-427$

447 Grostal P, Dicke M (2000) Recognising one's enemies: a functional approach to risk assessment by prey. Behav Ecol Sociobiol 47:258-264

449 Hamamura T (1986) Studies on the biological control of Kanzawa spider mite, 450 Tetranychus kanzawai Kishida by the chemical resistant predacious mite, Amblyseius longispinosus (Evans) in tea fields (Acarina: Tetranychidae, 

summary)

Hazan A, Gerson U Tahori AS (1974). Spider mite webbing. I. The production of webbing under various environmental conditions. Acarologia 16:68-84

Hodge MA, Storfer-Issera A (1997) Conspecific and heterospecific attraction: a mechanism of web-site selection leading to aggregation formation by web-building spiders. Ethology 103:815-826

Jeppson LR, Keifer HH, Baker EW (1975) Mites Injurious to Economic Plants. University of California Press, Berkeley

Kaplan I, Denno RF (2007) Interspecific interactions in phytophagous insects revisited: a quantitative assessment of competition theory. Ecol Lett 10:977-994

Kondo A, Takafuji A (1985) Resource utilization pattern of two species of tetranychid mites (Acari: Tetranychidae). Res Popul Ecol 27:145-157

Krams I, Krama T (2002) Interspecific reciprocity explains mobbing behaviour of 
468 Le Goff GJ, Mailleux A-C, Detrain C, Deneubourg J-L, Clotuche G, Hance T (2010)

469 Group effect on fertility, survival and silk production in the web spinner Tetranychus urticae (Acari: Tetranychidae) during colony foundation. Behaviour $147: 1169-1184$

Levins DA, MacArthur RH (1969) A hypothesis to explain the incidence of monophagy. Ecology 50:910-911

Margolies DC, Kennedy GG (1985) Movement of the two-spotted spider mite Tetranychus urticae Koch (Acari: Tetranychidae), among hosts in a corn-peanut agroecosystem. Entomol Exp Appl 37:55-61

McClure M, Despland E (2011) Defensive responses by a social caterpillars are tailored to different predators and change with larval instar and group size. Naturwissenschaften 98:425-434

McMurtry JA, Huffaker CB, van de Vrie M (1970) Ecology of tetranychid mites and their natural enemies: A review. I. Tetranychid enemies: their biological characters and the impact of spray particles. Hilgardia 40:331-390 
survival of young in the subsocial spider mite Schizotetranychus longus (Acari:

Morishita M (1992) Movement of two species of tetranychid mites (Acarina:

Morishita M (1997) Intercrop movement of the two-spotted spider mite, Tetranychus urticae Koch (Acari: Tetranychidae) from chrysanthemum to pea field. Jpn J Appl Entomol Zool 41:33-38 (in Japanese, with English summary) C, Haraguchi D, Yonamine K, Uezato T (2010) Non-crop host plants of Tetranychus spider mites (Acari: Tetranychidae) in the field in Okinawa, Japan: determination of possible sources of pest species and inference on the cause of peculiar mite fauna on crops. Appl Entomol Zool 45:465-475

Oku K, Yano S, Osakabe Mh, Takafuji A (2003) Spider mites assess predation risk by using the odor of injured conspecifics. J Chem Ecol 29:2609-2613 
Oku K, Magalhaes S, Dicke M (2009) The presence of webbing affects the oviposition rate of two-spotted spider mites, Tetranychus urticae (Acari: Tetranychidae). Exp Appl Acarol 49:167-172

Osakabe Mh (1988) Relationships between food substances and developmental success in Amblyseius sojaensis Ehara (Acarina: Phytoseiidae). Appl Entomol Zool 23:45-51

Osakabe Mh, Inoue K, Ashihara W (1986) Feeding, reproduction and development of Amblyseius sojaensis Ehara (Acarina: Phytoseiidae) on two species of spider mites and on tea pollen. Appl Entomol Zool 21:322-327 species (Acari: Tetranychidae) using PCR-RFLP of the inter-transcribed spacer region of nuclear ribosomal DNA. Appl Entomol Zool 37:399-407

514 Ozawa A, Takafuji A (1987) Inter-specific crosses between Tetranychus urticae 
517 Ozawa M, Yano S (2009) Pearl bodies of Cayratia japonica (Thunb.) Gagnep.

Pallini A, Janssen A, Sabelis MW (1999) Spider mites avoid plants with predators.

Pratt PD, Croft BA (1999) Expanded distribution of the bamboo spider mite, fallacies (Acari: Phytoseiidae). Acarologia 40:191-197

Prokopy RJ, Roitberg BD (2001) Joining and avoiding behavior in non-social insects.

Rasa OA (1997) Aggregation in a desert tenebrionid beetle: a cost/benefit analysis. 
532 Sabelis MW, Bakker FM (1992) How predatory mites cope with the web of their tetranychid prey: a fubctional view on dorsal chaetotaxy in the Phytoseiidae.

Saito Y (1983) The concept of "life types” in Tetranychidae. An attempt to classify

Saito Y (1986a) Biparental defence in a spider mite (Acari: Tetranychidae) infesting

Saito Y (1986b) Prey kills predator: counter-attack success of a spider mite against

SAS Institute Inc (1998) SAS/STAT user's guide, release 6.03 edition. SAS Institute,

Semeniuk CAD, Dill LM (2004) Cost/benefit analysis of group and solitary resting in the cowtail stingray, Pastinachus sephen. Behav Ecol 16:417-426 
548 Spieler M (2003) Risk of predation affects aggregation size: a study with tadpoles of

Strong WB, Croft BA, Slone DH (1997) Spatial aggregation and refugia of the mites Tetranychus urticae and Neoseiulus fallacis (Acari: Tetranychidae, Phytoseiidae) on hop. Environ Entomol 26:859-865 mites (Acari: Tetranychidae) on different host plants. Appl Entomol Zool $36: 169-175$

Tilman D (1982) Resource Competition and Community Structure. Princeton myrmecophytic melastome, and one of its ant inhabitants: ant protection against insect herbivores. Oecologia 87:295-298

561 Yano S (2008) Collective and solitary behaviors of the two-spotted spider mite 
564 Yano S, Wakabayashi M, Takabayashi J, Takafuji A (1998) Factors determining the

565 host plant range of the phytophagous mite, Tetranychus urticae Koch (Acari:

566 Tetranychidae). A method for quantifying host plant acceptance. Exp Appl

567

Acarol 22:595-602

568

Yano S, Kanaya M, Takafuji A (2003) Genetic basis of color variation in leaf scars

569

induced by the Kanzawa spider mite. Entomol Exp Appl 106:37-44

570 


\section{$571 \quad$ Figure Legends}

572 Fig. 1 A preliminary test confirming predation saturation over time. There was no

573 predation of spider mite females after the initial $12 \mathrm{~h}$. Hence, predation rate was

574 measured subsequently $24 \mathrm{~h}$ after predator introduction.

575

576 Fig. 2 Effects of group size and webs on predation rates on spider mites. Bars

577 indicate per capita predation rate on active (a) T. urticae and (b) T. kanzawai with

578 different group sizes and time lags for web building. Decreased predation with

579 increased time lag indicates that completed webs may effectively defend spider mites

580 from predation while decreased (per capita) predation with increasing group size

581 indicates a dilution effect.

582

583 Fig. 3 Degree of spider mite group living in response to a predator. Distances

584 between conspecific spider mites are shown in relation to predator presence 1 , 4 , and

to predator presence, although the differences became less obvious over time after 
predator introduction.

588

589 Fig. 4 Indirect interactions between spider mites sharing a web in the absence of a

590 predator. The number of eggs laid by a test female within $24 \mathrm{~h}$ did not differ among

591 treatments for either a T. urticae and b T. kanzawai, indicating that there was

592 virtually no indirect interaction between heterospecific and conspecific mites sharing

593 fresh webs.

594

595 Fig. 5 Do spider mites living together distinguish between species? Lines indicate

596 distances between spider mite females. There were no significant differences among

597 the three groups at any point, suggesting that spider mite females living together do

598 not distinguish between species. 


\section{Fig.1}

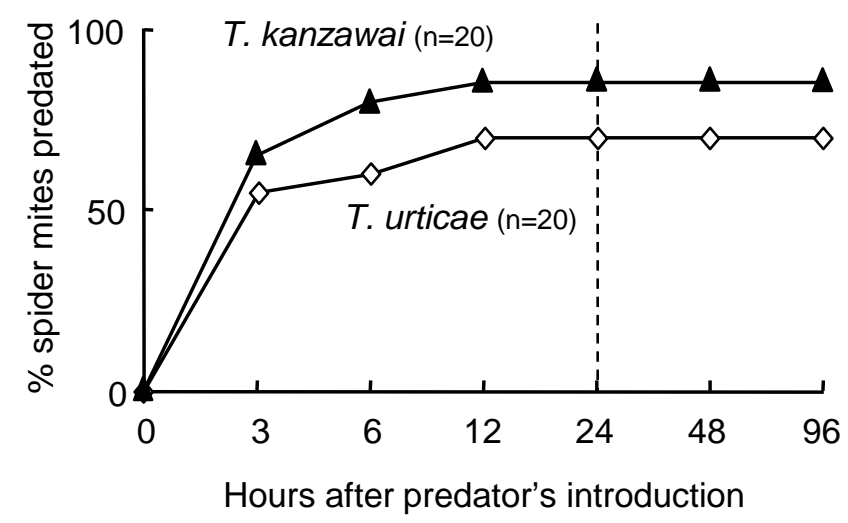


Fig.2

a) T. urticae

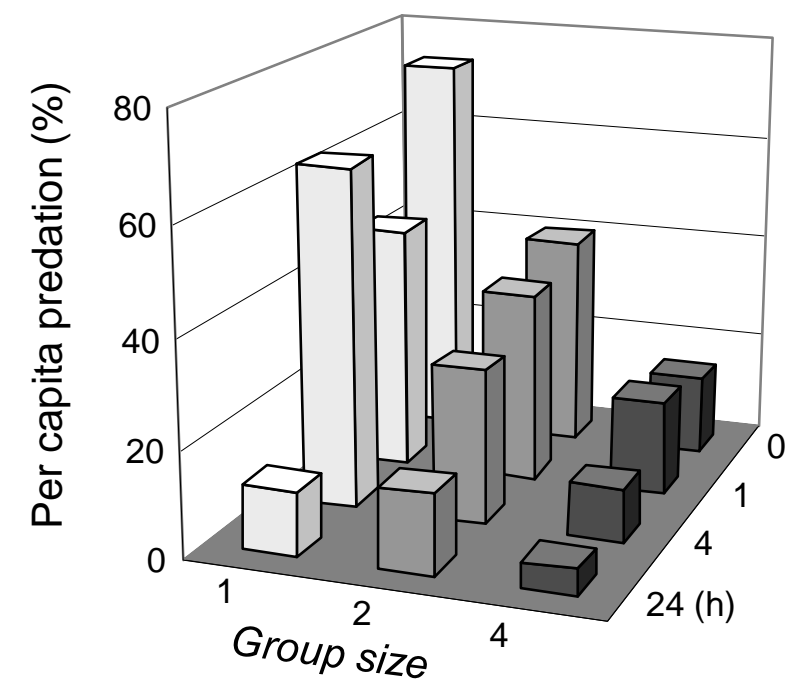

b) T. kanzawai

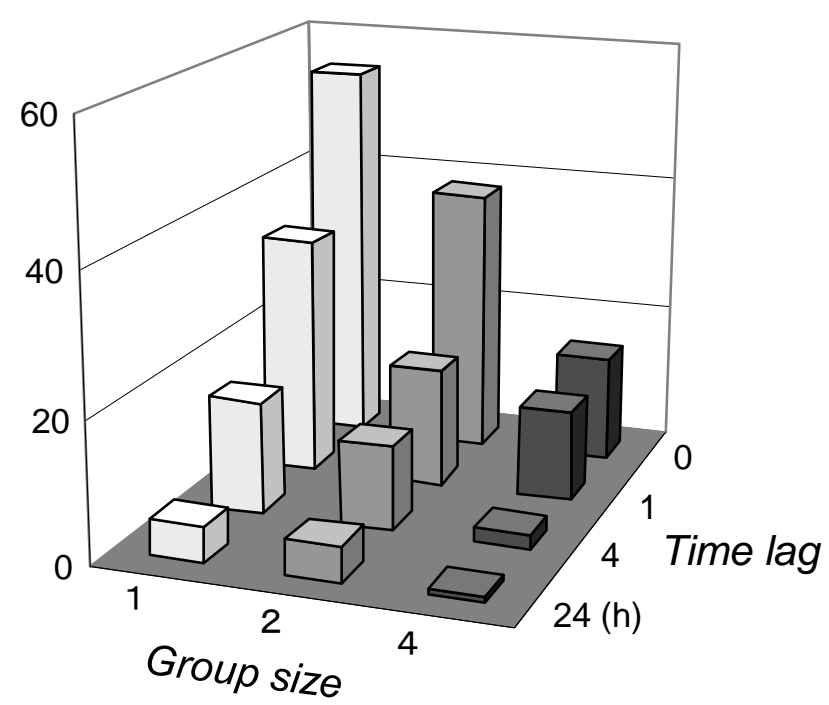


Fig.3

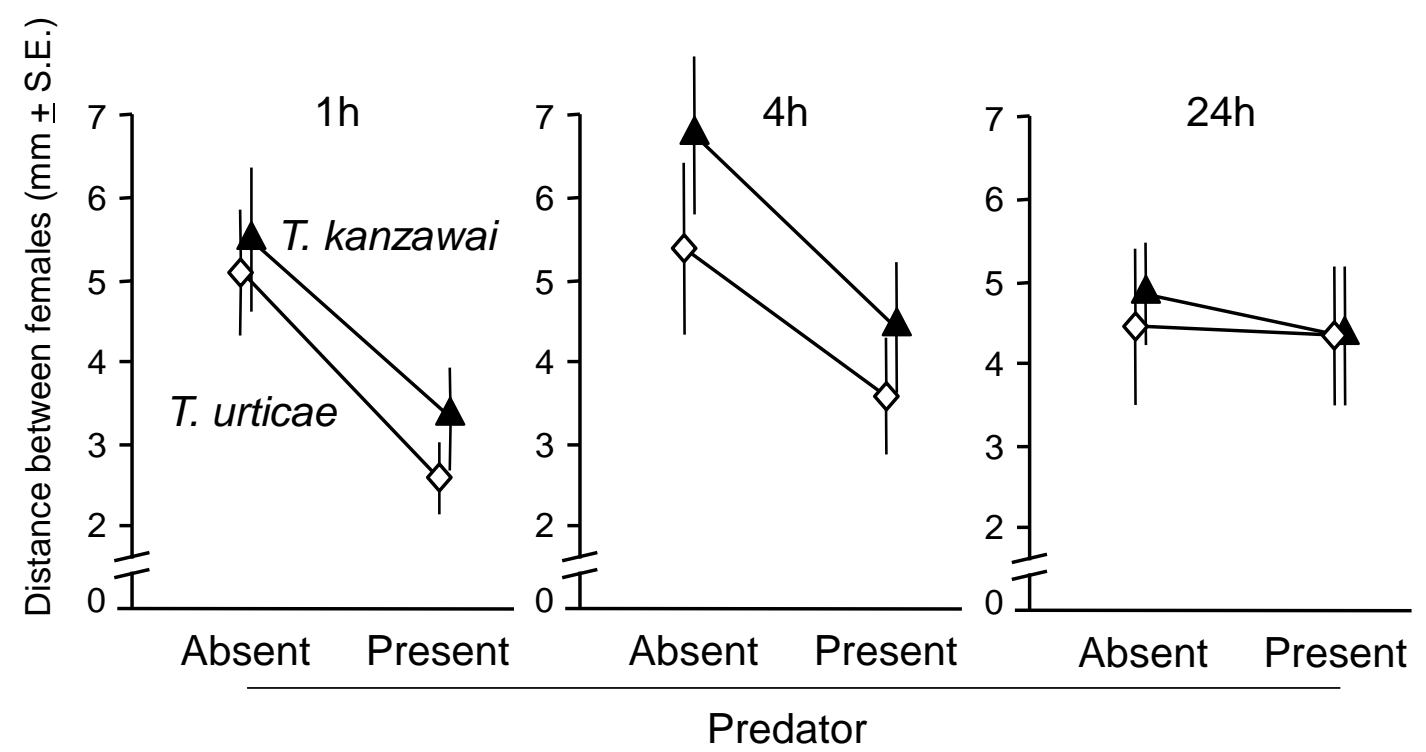


Fig.4
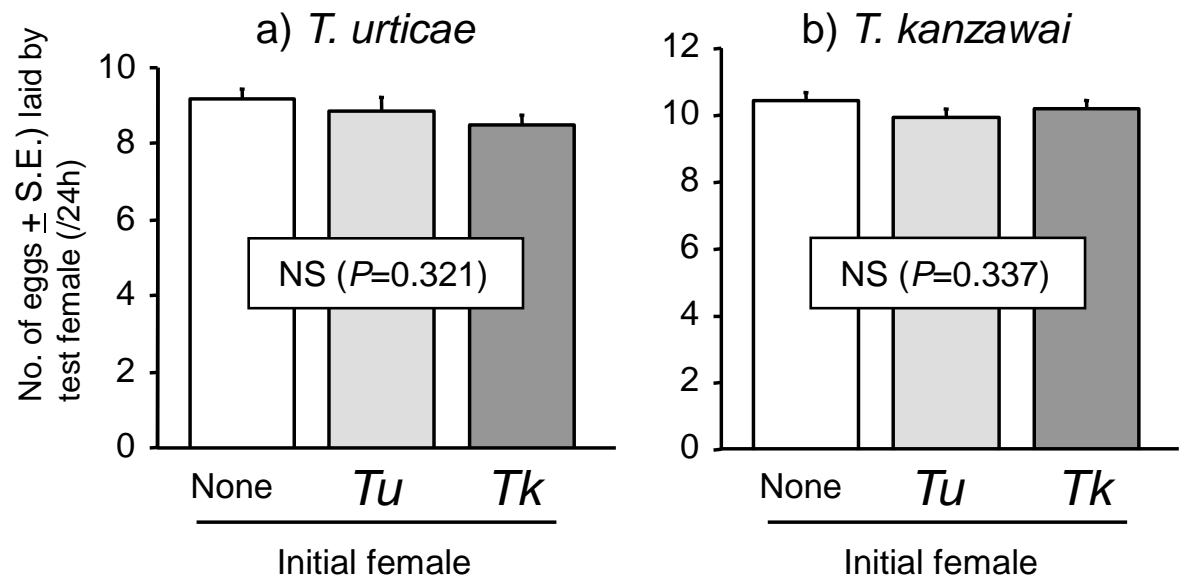


\section{Fig.5}

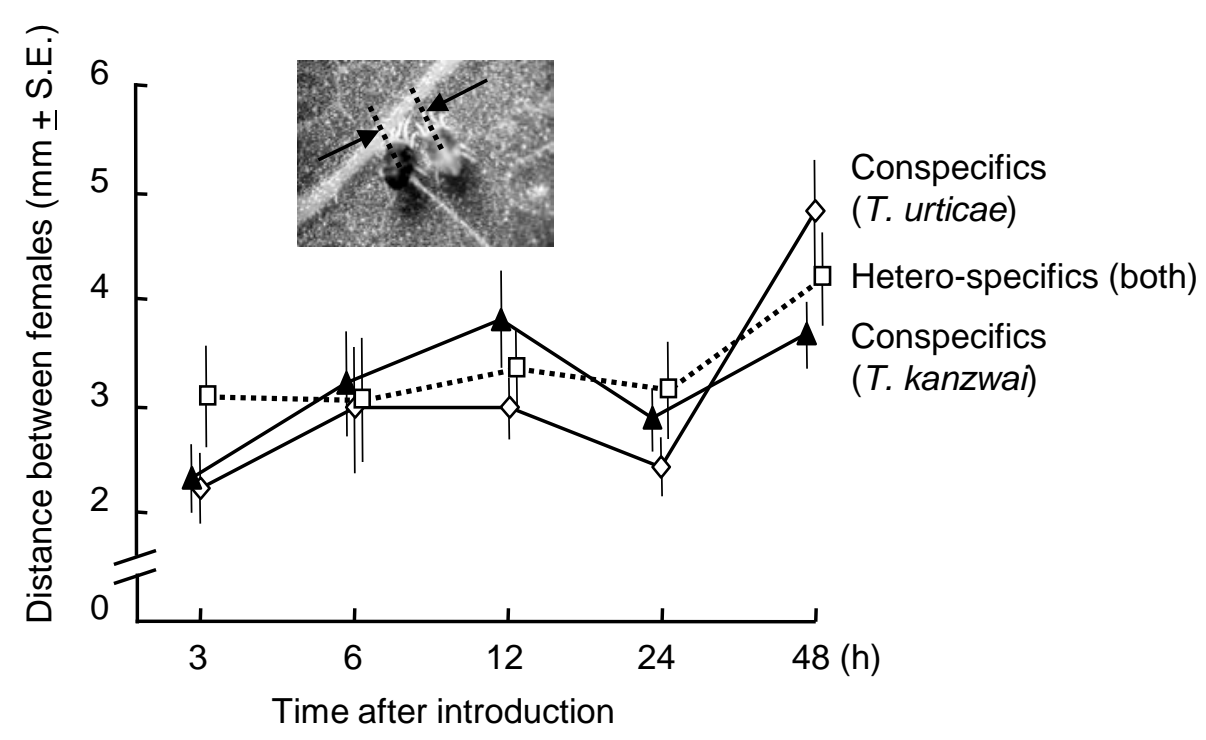

